http://jmscr.igmpublication.org/home/

ISSN (e)-2347-176x ISSN (p) 2455-0450

crossref DOI: https://dx.doi.org/10.18535/jmscr/v8i11.10

Journal Of Medical Science And Clinical Research

IGM Publication

An Official Publication of IGM Publication

\title{
A Clinicopathological Study of Endometrial Hyperplasia in a Rural Teaching Hospital
}

\section{Authors \\ S. Kayalvizhi ${ }^{1}$, B.Krishnaswamy ${ }^{2}$, U. Manohar ${ }^{3}$, M. Dhanalakshmi ${ }^{4}$, Valluvan Manimozhi ${ }^{5}$}

${ }^{1}$ Final Year Post Graduate, Department of Pathology, Rajah Muthiah Medical College, Annamalai University

${ }^{2}$ Professor \& Head, Department of Pathology, Rajah Muthiah Medical College, Annamalai University

${ }^{3,4}$ Professor, Department of Pathology, Rajah Muthiah Medical College, Annamalai University

${ }^{5}$ Assistant Professor, Department of Pathology, Rajah Muthiah Medical College, Annamalai University

\begin{abstract}
Introduction: Endometrial hyperplasia is defined as an increase in the number of glands relative to stroma, appreciated as crowded glands, often with abnormal shapes. It is an important cause for abnormal uterine bleeding. It is divided into non -atypical and atypical based on nuclear atypia. Atypical hyperplasia is associated with increased risk of endometrial carcinoma.

Aims and Objectives: The present study was conducted to study the relative occurrence of endometrial hyperplasia and to evaluate the histopathological patterns of different types of endometrial hyperplasia. Materials and Methods: This is a prospective study includes endometrial biopsy samples (13) and hysterectomy specimens (1) of abnormal uterine bleeding cases diagnosed as endometrial hyperplasia.

Results: Endometrial hyperplasia was observed in the age group of 31-40 years followed by that of 4150 years. The most frequent clinical diagnosis was menorrhagia (HMB). The leading pathology was identified as simple endometrial hyperplasia without atypia.

Keywords: Abnormal uterine bleeding, Endometrial carcinoma, Gland architecture, Atypia.
\end{abstract}

\section{Introduction}

Endometrial hyperplasia is defined as an increased proliferation of the endometrial glands relative to the stroma, resulting in an increased gland to stroma ratio when compared with normal proliferative endometrium. ${ }^{(1)}$ Endometrial hyperplasia is most commonly seen in both premenopausal and postmenopausal women. ${ }^{(2)}$ Endometrial hyperplasia is further classified on the basis of the complexity of endometrial glands and any cytological atypia, resulting in a classification system of simple or complex hyperplasia, with or without atypia. The current classification of endometrial hyperplasia includes endometrial hyperplasia without atypia, atypical hyperplasia, endometrioid intraepithelial neoplasia. $^{(1)}$

The most common presenting symptom of endometrial hyperplasia irrespective of classification is abnormal uterine bleeding. Any alteration in regularity, frequency of menses, duration of flow, and amount of blood loss, is called abnormal uterine bleeding (AUB); symptom and not a disease ${ }^{(4)}$. AUB is categorized 
into two broad groups. First is due to organic causes having some pathology like fibroid, adenomyosis, endometrial hyperplasia, endometrial carcinoma,etc. Secondly dysfunctional uterine bleeding (DUB) when there is absence of organic disease of the genital tract. ${ }^{(5)}$ The probability of progression of endometrial hyperplasia to adenocarcinoma is related to the degree of architectural or cytological atypia. Diagnostic hysteroscopic biopsy is the gold standard investigation for endometrial cavity evaluation and to exclude endometrial hyperplasia or endometrial carcinoma. ${ }^{(2)}$

\section{Aims and Objectives}

The present study was conducted to study the clinical profile and relative occurrence of endometrial hyperplasia and to evaluate the histopathological patterns of different types of endometrial hyperplasia.

\section{Materials and Methods}

Clinicopathological evaluation of endometrial hyperplasia with abnormal uterine bleeding was conducted during the period of December 2018 to May 2020 in the department of pathology, RMMCH, Chidambaram. The study material for the present study were endometrial biopsy samples (13) and hysterectomy specimens (1) of abnormal uterine bleeding cases diagnosed as endometrial hyperplasia. These specimens were included in the study after conventional tissue processing, standard staining by haematoxylin and eosin ( $\mathrm{H}$ and $\mathrm{E}$ ), and examination by light microscopy. Inadequate specimen, improperly processed specimen, and cases with insufficient clinical data were excluded from the study. Histological typing of endometrial hyperplasia was done depending on the criteria used in WHO classification $^{(6)}$.

\section{Results}

The present study included 14 cases of endometrial hyperplasia diagnosed by histopathological examination on endometrial curettage samples and hysterectomy specimens. The maximum frequency (50\%, 7 out of 14) was observed in the age group of 31-40 years followed by that of $41-50$ years $(43 \%$, 6out of 14$)$. The most frequent clinical diagnosis was menorrhagia (HMB) (36\%, 5 out of 14). Oligomenorrhoea came out as the next common complaint (22\%, 3 out of 14). The leading pathology was identified as simple endometrial hyperplasia without atypia (79\%, 11 out of 14 cases) (Table 3). We observed each 1 case $(7 \%)$ of complex endometrial hyperplasia without atypia, simple hyperplasia with atypia and complex endometrial hyperplasia with atypia. Distribution of the study population according to gland architecture, and the presence and extent of cytological atypia are depicted in Tables 4 and Table 5 respectively.

Table 1: Age distribution pattern

\begin{tabular}{|l|c|c|}
\hline Age (years) & No. of cases & Percentage \\
\hline 31 to 40 & 7 & 50 \\
\hline 41 to 50 & 6 & 43 \\
\hline 51 and above & 1 & 7 \\
\hline
\end{tabular}

Graph 1: Age Distribution Pattern

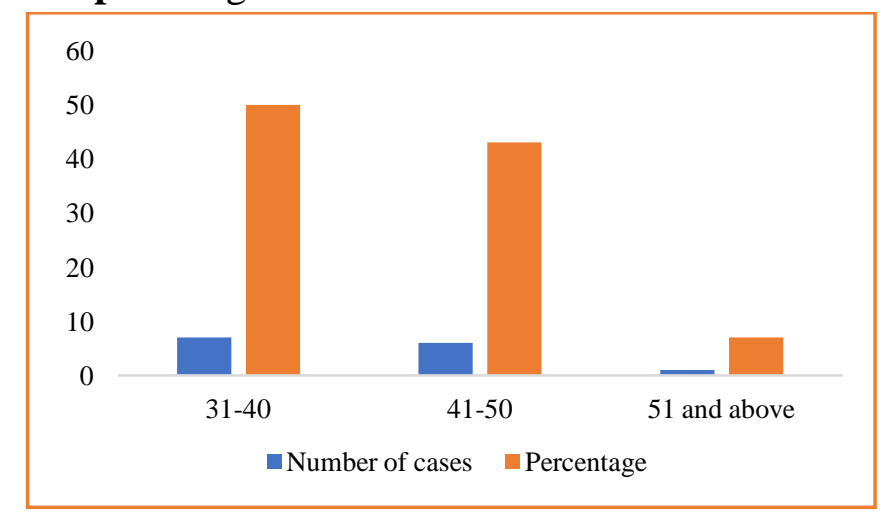


Table 2: Distribution of bleeding patterns

\begin{tabular}{|l|c|c|}
\hline Symptoms & No. of cases & Percentage \\
\hline Heavy menstrual bleeding (HMB) & 5 & 36 \\
\hline Inter menstrual bleeding (IMB ) & 2 & 14 \\
\hline Frequent menstrual bleeding (FMB) & 2 & 14 \\
\hline Heavy \& prolonged bleeding (HMB + PB) & 2 & 14 \\
\hline Oligomenorrhoea & 3 & 22 \\
\hline
\end{tabular}

Graph 2: Distribution of bleeding patterns

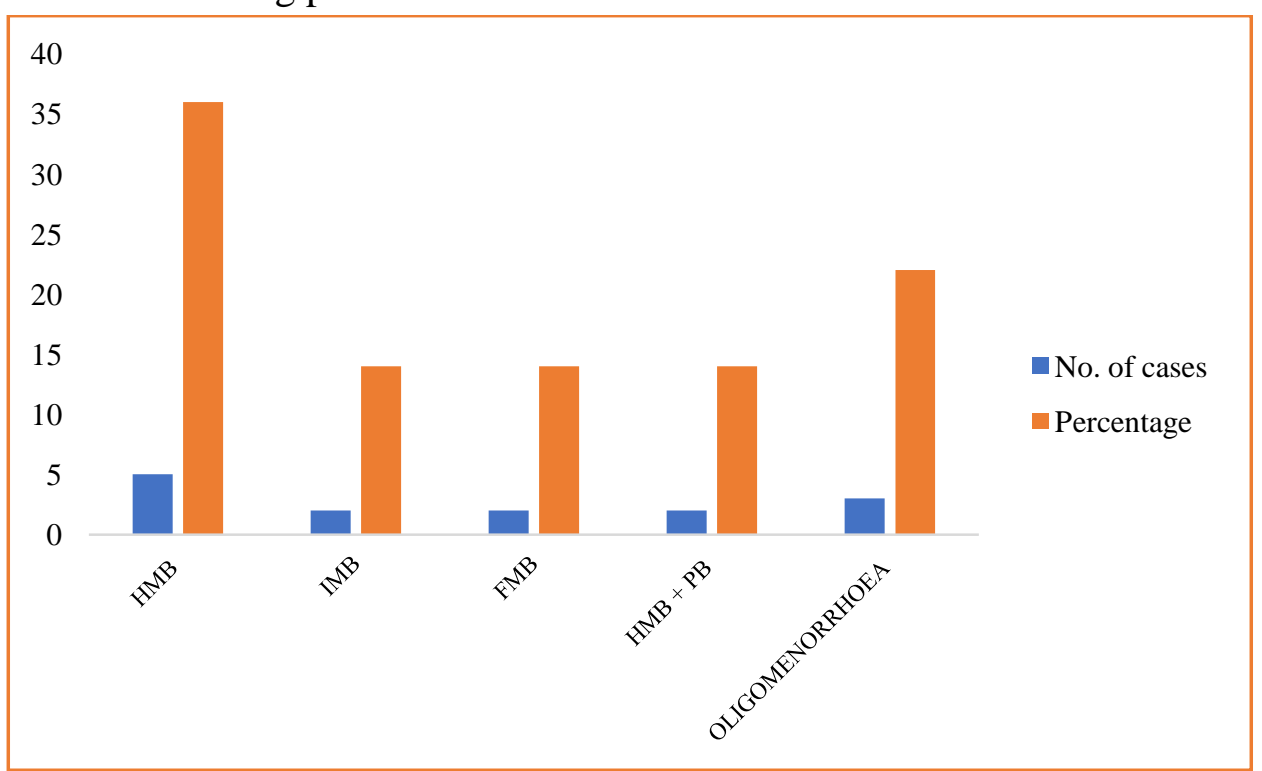

Table 3: Pattern of endometrial hyperplasia in AUB

\begin{tabular}{|l|c|c|}
\hline Types of endometrial hyperplasia & No. of cases & Percentage \\
\hline Simple hyperplasia without atypia & 11 & 79 \\
\hline Simple hyperplasia with atypia & 1 & 7 \\
\hline Complex hyperplasia without atypia & 1 & 7 \\
\hline Complex hyperplasia with atypia & 1 & 7 \\
\hline
\end{tabular}

Graph 3: Pattern of endometrial hyperplasia in AUB

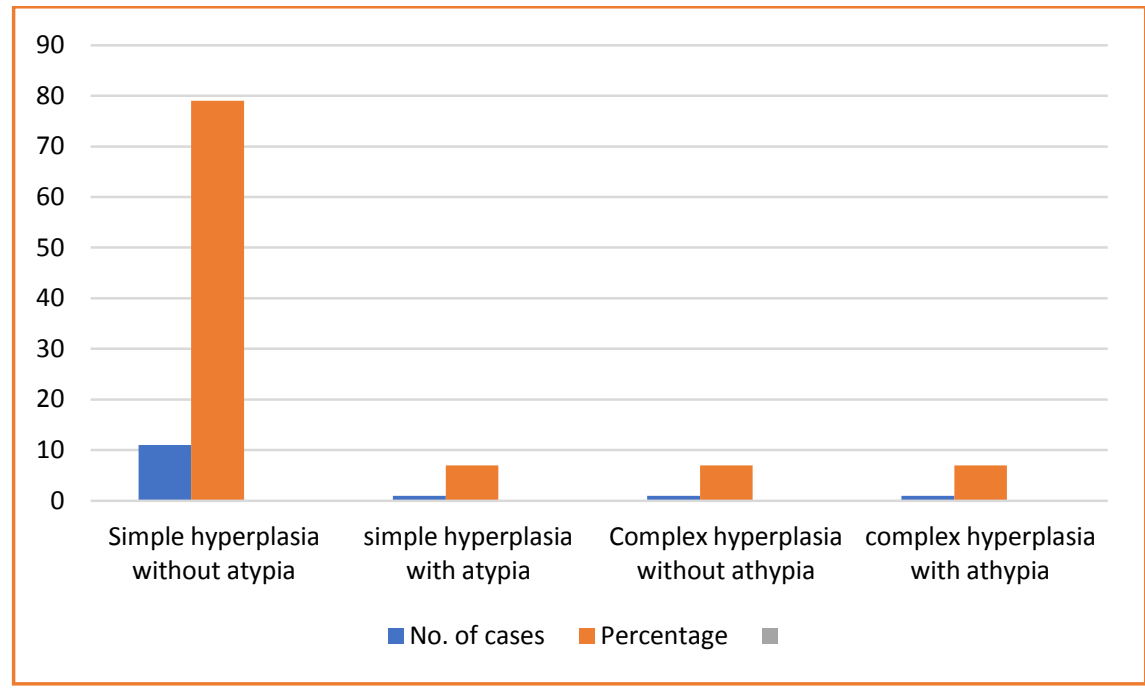


Table 4: Distribution of cases according to gland architecture

\begin{tabular}{|l|c|c|}
\hline Gland architecture & No. of cases & Percentage \\
\hline Complex with branching & 2 & 14 \\
\hline Variable size & 4 & 29 \\
\hline Variable size with outpouching & 3 & 21 \\
\hline Variable size with cystic dilatation & 5 & 36 \\
\hline
\end{tabular}

Graph 4: Distribution of cases according to gland architecture

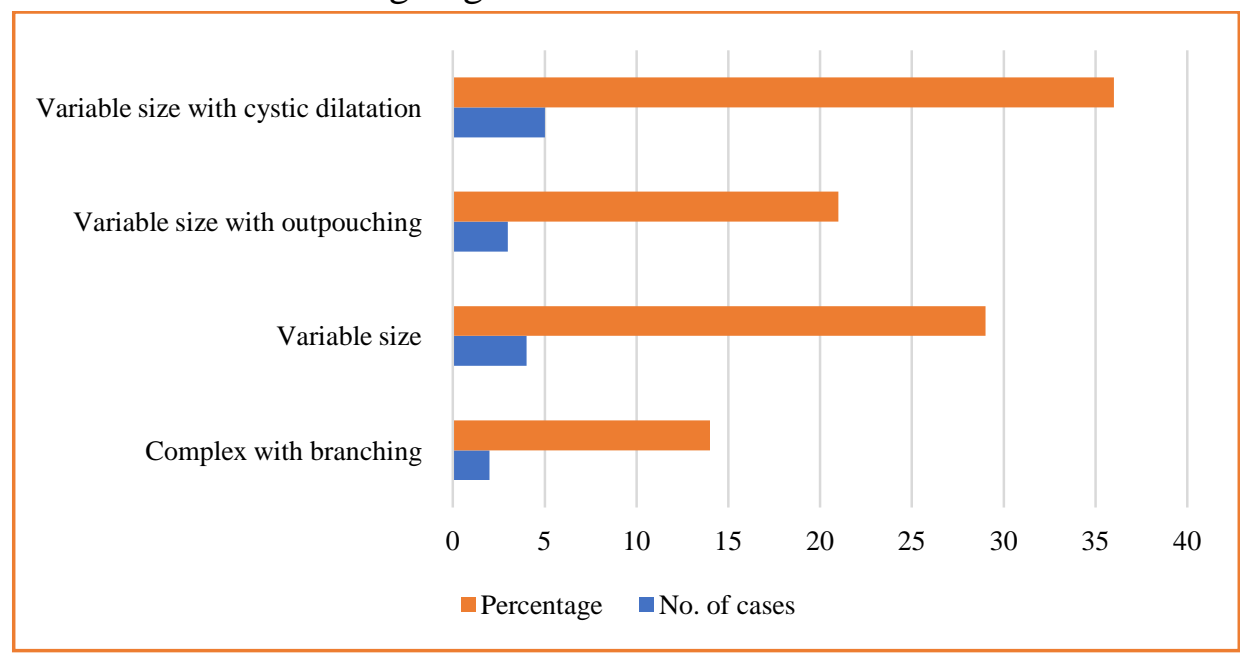

Table 5: Distribution of cases according to the presence and extent of atypia

\begin{tabular}{|l|c|c|}
\hline Atypia & No. of cases & Percentage \\
\hline Absent & 12 & 86 \\
\hline Mild & 2 & 14 \\
\hline Moderate & 0 & - \\
\hline Severe & 0 & - \\
\hline
\end{tabular}

Graph 5: Distribution of cases according to the presence and extent of atypia

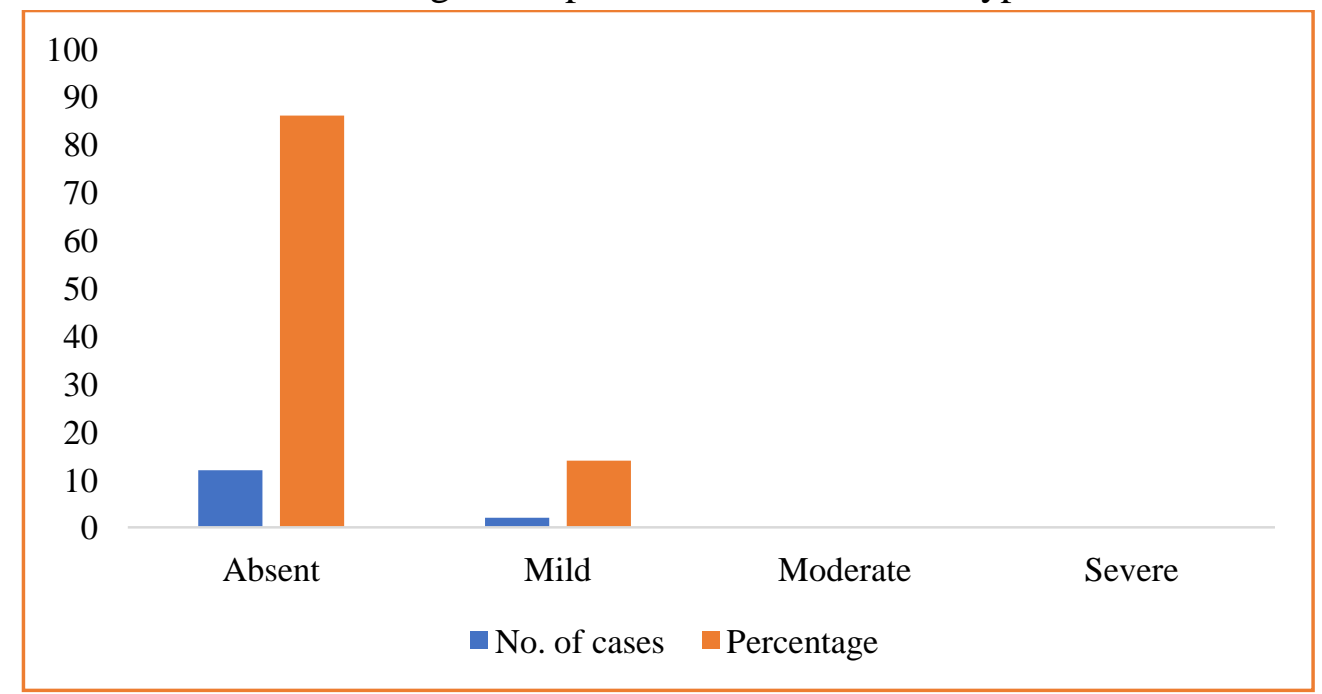




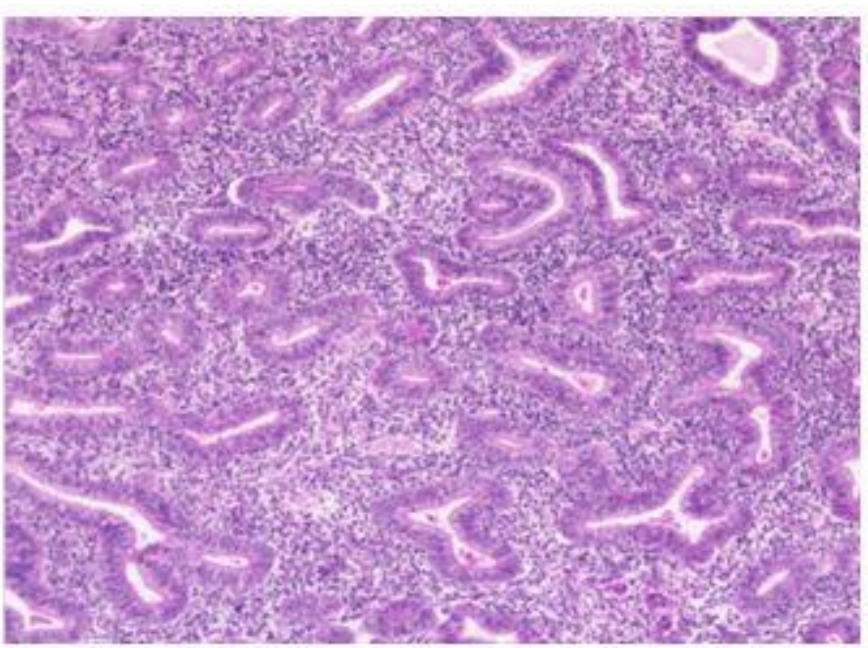

Figure 1 Complex endometrial hyperplasia without atypia

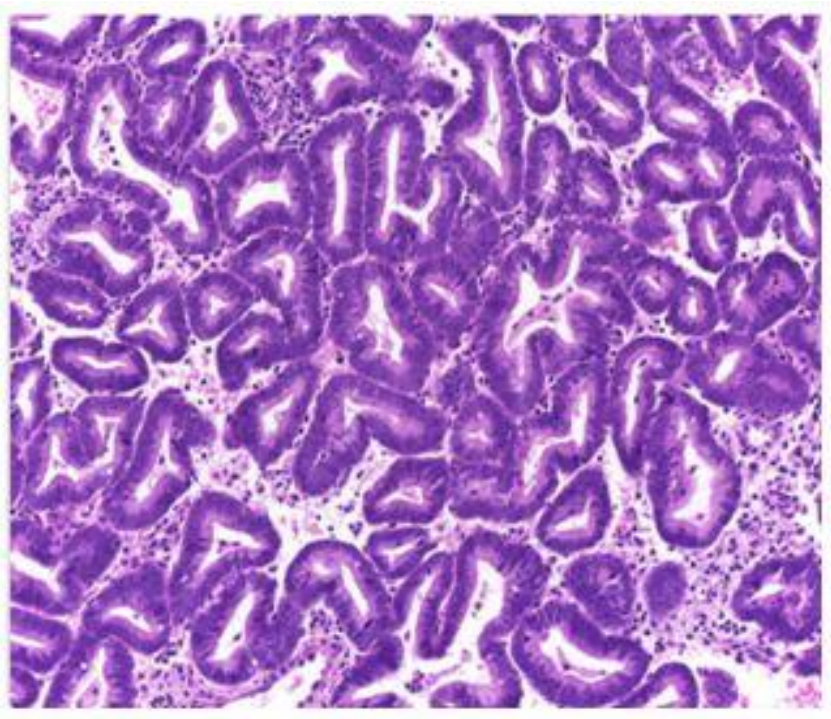

Figure 2 Complex endometrial hyperplasia with atypia

\section{Discussion}

The age distribution of endometrial hyperplasia in the present study revealed that the commonest age group to be 31-40 years (50\%), followed by $41-50$ years (43\%). Kurman et al. ${ }^{(7)}$, Gargi Raychaudhuri et al. ${ }^{(1)}$ found that the commonest age group was 41-50 years which is not in concordance with the present study.

Takreem et al. ${ }^{(8)}$, and Gargi Raychaudhari et al. ${ }^{(1)}$ found out that menorrhagia is the commonest complaint in endometrial hyperplasia $(53.3 \%$, 49.6\% respectively). Muzaffar et al. ${ }^{(9)}$ found that endometrial hyperplasia was one of the leading pathologies in women suffering from abnormal uterine bleeding. Their study revealed that $24.7 \%$ of such cases were caused by endometrial hyperplasia. They also found that menometrorrhagia was the commonest presenting complaint in endometrial hyperplasia followed by polymenorrhoea. In our study, $36 \%$ of patients presented with menorrhagia followed by oligomenorrhoea.

Takreem et al. ${ }^{(8)}$ and Gargi Raychaudhari et al. ${ }^{(1)}$ found that simple hyperplasia without atypia was the commonest $(66.6 \%, 95.6 \%$ respectively) pattern of hyperplasia which is in concordance with our study also. Singh et al. ${ }^{(3)}$ reported that both simple and complex hyperplasia with or without atypia are known to be precancerous lesion of endometrial carcinoma and are reported to be 1 to $3 \%$ in hyperplasia without atypia and 8 to $29 \%$ in hyperplasia with atypia.

According to gland architecture Gargi Raychaudhari et al. ${ }^{(1)}$ reported that variable size with cystic dilatation $(60.4 \%)$ is the commonest type which is concordance with our study also $(35.7 \%)$.

Gargi Raychaudhari et al also reported that endometrial hyperplasia without atypia in $99.2 \%$ and mild and moderate atypia in $0.4 \%$ cases. In our study endometrial hyperplasia without atypia is $86 \%$ followed by mild atypia in $14 \%$ cases.

Chamlian and Taylor ${ }^{(10)}$, in a long-term study, found that $14 \%$ adenomatous and atypical hyperplasias subsequently developed into carcinoma. Other studies have reported the highest risks of progression to carcinoma in the atypical hyperplasia group, as well as the highest risk of persistence of the lesion despite hormonal therapy (11)

We plan to continue our study later including further follow-up to find out relationship between endometrial hyperplasia and carcinoma.

\section{Limitations of Our Study}

1. Small sample size

2. Long term follow-up needed to find the relationship between endometrial hyperplasia and carcinoma 


\section{Conclusion}

This study showed that most of the patients fall in the age group 31-40 years, followed by 41-50 years and most commonly presenting with menorrhagia. The incidence of endometrial hyperplasia peaks around perimenopausal age group. Endometrial hyperplasia is the precursor of endometrial carcinoma, hence endometrial cavity evaluation should be done at more than 40 years of age. Though the frequency of atypical hyperplasia was very low compared to simple hyperplasia without atypia, in our present study we recommend further long-term follow-up study.

\section{References}

1. Raychaudhuri, Gargi et al. "Endometrial hyperplasia: a clinicopathological study in a tertiary care hospital." Journal of obstetrics and gynaecology of India vol. 63, 6 (2013): 394-8. doi:10.1007/s13224013-0414-2

2. Markandu, Thirukumar \& Ahilan, Sinnathurai. (2018). Histopathological Pattern of Endometrium: Hospital Based Study in Teaching Hospital, Batticaloa, Srilanka. Open Journal of Obstetrics and Gynecology. $\quad 08 . \quad 1015-1022$. 10.4236/ojog.2018.811102.

3. Singh, Kanika et al. "A Clinicopathological Correlation of International Federation of Gynecology and Obstetrics's PALM-COEIN Classification of Abnormal Uterine Bleeding: Indian Scenario." Journal of mid-life health vol. 10, 3 (2019): 147-152. doi:10.4103/jmh.JMH_128_18

4. Puvitha.R.D., Elavarasan. T., Shruthi. M.S., Shylaja.S. Histopathological Study of Endometrium in Abnormal Uterine Bleeding An Experience in a Tertiary Care Centre of Rural South India. ISSN : 09766626 (print), 2455-1740

5. Ajit Kumar Nayak, Kalyani Hazra, Manju Kumari Jain. Clinico-pathological evaluation of dysfunctional uterine bleeding. International Journal of Contemporary Medical Research 2017;4(4):920-924

6. Kurman RJ, Kaminski PF, Norris HJ. The behavior of endometrial hyperplasia. A long-term study of "untreated" hyperplasia in 170 patients. Cancer. 1985;56:403-12

7. Takreem A, Danish N, Razaq S. Incidence of endometrial hyperplasia in 100 cases presenting with polymenorrhagia/ menorrhagia in perimenupausal women. $\mathrm{J}$ Ayub Med Coll Abbottabad. 2009;21:60-3

8. Muzaffar M, Akhtar KA, Yasmin S, et al. Menstrual irregularities with excessive blood loss: a clinico-pathological correlation. J Pak Med Assoc. 2005; 55: 486-9

9. Chamlian DL, Taylor HB. Endometrial hyperplasia in young women. Obstet Gynecol. 1970;36:659-66

10. Mutter GL. Endometrial intraepithelial neoplasia (EIN): will it bring order to chaos? The Endometrial Collaborative Group. Gynecol Oncol. 2000; 76:287-90. 